\title{
VALERIA GRAMIGNA, Scritture in ascolto. Sentimenti e musica nella prosa francese contemporanea
}

\section{Nicola Ferrari}

\section{(2) OpenEdition}

\section{Journals}

\section{Edizione digitale}

URL: https://journals.openedition.org/studifrancesi/32303

DOI: 10.4000/studifrancesi.32303

ISSN: 2427-5856

\section{Editore}

Rosenberg \& Sellier

\section{Edizione cartacea}

Data di pubblicazione: 1 août 2020

Paginazione: 443-444

ISSN: 0039-2944

\section{Notizia bibliografica digitale}

Nicola Ferrari, «VALERIA GrAmigna, Scritture in ascolto. Sentimenti e musica nella prosa francese

contemporanea», Studi Francesi [Online], 191 (LXIV | II) | 2020, online dal 01 septembre 2020, consultato il 18 septembre 2021. URL: http://journals.openedition.org/studifrancesi/32303 ; DOI: https://doi.org/ 10.4000/studifrancesi.32303

Questo documento è stato generato automaticamente il 18 septembre 2021.

\section{(c) $($ ) $(9)$}

Studi Francesi è distribuita con Licenza Creative Commons Attribuzione - Non commerciale - Non opere derivate 4.0 Internazionale. 


\title{
VALERIA GRAMIGNA, Scritture in ascolto. Sentimenti e musica nella prosa francese contemporanea
}

\author{
Nicola Ferrari
}

\section{NOTIZIA}

VALERIA GRAMIGNA, Scritture in ascolto. Sentimenti e musica nella prosa francese contemporanea, Macerata, Quodlibet, 2019, 196 pp.

1 Quaranta testi francesi, dalla fine degli anni Novanta al 2015, che, nel frastagliato e cangiante territorio dell'"estremo contemporaneo" in attesa di sempre più accurate cartografie, dimostrano la volontà di sperimentare nuovi paradigmi di scrittura, rendendo ancora cruciale la questione dell'attualità del romanzo. Quaranta testi, capaci di superare la nostalgia per ogni mimesi ingenua, lacerando il tessuto della frase, sospendendo la linearità della narrazione, spezzando la tradizionale continuità di discorso in fluidi processi di risonanza e deriva semantica, sintattica, fonetica. Quaranta testi da ascoltare con orecchio teso alle dinamiche sforzate di punteggiatura, al fraseggio sghembo delle costruzioni, alle dissonanze lessicali, per capire i diversi modi nei quali, oggi, a distanza, cronologica e poetica, dalle grandi esperienze del primo e secondo Novecento, la prosa possa ancora dirsi "musicale". Questi testi, attraverso partecipate analisi stilistiche e informate indagini peri- e paratestuali, tanto in relazione alle dichiarate intenzioni autoriali quanto alle strategie di collocazione e presentazione editoriale, vengono esplorati nella loro dimensione di dispositivi romanzeschi costruiti sulla relazione musica-parola; interrogandoli sul se, sul come e il perché, la musica possa (o voglia) costituire un catalizzatore formale della scrittura letteraria.

2 Affrontata da molteplici prospettive analitiche (tematiche, morfologiche, psicologiche), la relazione tra forma narrativa e dimensione acustico-musicale sembrerebbe 
determinare, oltre a una generale, energizzante, propulsione creativa, una specifica capacità di articolare, dilatare, esplorare la relazione affettiva tra le emozioni dell'individuo e della collettività di cui fa parte: attraverso il confronto con i processi memoriali legati al suono e le differenti forme musicali, le narrazioni musicali permettono di mettere in relazione peculiari esperienze individuali (nei testi analizzati di Sorman, Savelli, Cathrine, Adam, Schuhl, Delaume, Detambel, Schwartz, Willems, Wajsbrot) con la dimensione storica e sociale nella quale si proiettano (in Huston, Makine, Ernaux, Laurens, Rouaud, Kerangal, Énard), rivelandosi sensibili partiture della nostra contemporaneità da ascoltare nella sua irriducibile complessità ritmica $\mathrm{e}$ polifonica (in Dominique A, Galéa, Bonnerave, Meurisse, Benyahya, Bailly, Martinez, Houdart). 